Revista Tecné, Episteme y Didaxis: TED. Año 2014, Número Extraordinario. ISSN Impreso: 0121-3814, ISSN web: 2323-0126

Memorias, Sexto Congreso Internacional sobre Formación de Profesores de Ciencias. 08 al 10 de octubre de 2014, Bogotá

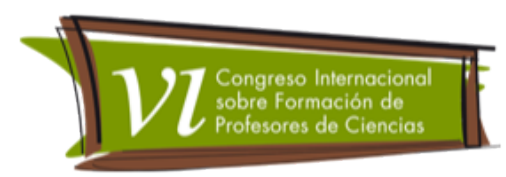

\title{
Corpo, gênero e sexualidade na escola: sob um fio de malabarismo em sala de aula
}

Santos, Fernanda Figueredo dos'; Souza, Marcos Lopes de²

Categoria 1. Reflexões e experiências de inovação na sala de aula.

\section{Resumo}

Este trabalho apresenta e analisa uma proposta de abordagem das questões de corpo, gênero e sexualidade vislumbrada em romper com o enfoque biologizante e higienista, questionando o olhar regulatório, padronizador e heteronormativo na escola. A intervenção foi desenvolvida nas aulas de Ciências de uma turma do $8^{\circ}$ e $9^{\circ}$ ano do ensino fundamental da Educação de Jovens e Adultos (EJA) de uma escola pública de Jequié-BA/Brasil. Pautando-se em uma perspectiva desestabilizadora, dialógica e problematizadora, a proposta revelou desafios "malabaristas", pois a sexualidade, a identificação de gênero e o fazer docente da pesquisadora foram colocados "sob suspeita". Ao mesmo tempo, a proposta provocou novas reflexões ao trazer as múltiplas possibilidades de compreensão e vivência dos corpos, dos gêneros e dos desejos e prazeres envolvendo as sexualidades.

\section{Palavras-chave}

Educação sexual, prática educativa e ensino de Ciências.

\section{Introdução}

Com base no pressuposto de que as questões sobre corpo, gênero e sexualidades se definem em um âmbito biológico, social, cultural e político, é relevante que os espaços educativos formais abordem estas discussões questionando o olhar regulatório e heteronormativo dos corpos.

Pesquisas indicam que a temática é, prioritariamente, tratada na disciplina de Ciências, enfocando conhecimentos como modelos idealizados dos corpos,

\footnotetext{
1 Universidade Estadual do Sudoeste da Bahia. figueredo.fernanda.santos@gmail.com.

${ }^{2}$ Universidade Estadual do Sudoeste da Bahia. marcoslsouza@ig.com.br.
} 
Revista Tecné, Episteme y Didaxis: TED. Año 2014, Número Extraordinario. ISSN Impreso: 0121-3814, ISSN web: 2323-0126

Memorias, Sexto Congreso Internacional sobre Formación de Profesores de Ciencias. 08 al 10 de octubre de 2014, Bogotá

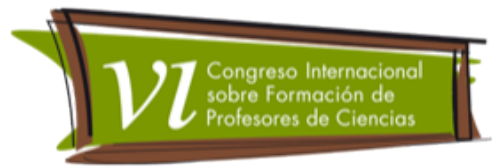

métodos contraceptivos e doenças sexualmente transmissíveis. Geralmente, a preocupação maior é controlar a gravidez e evitar o contágio de doenças (Silva \& Megid Neto, 2006).

Nessa perspectiva, trabalhos como os de Silva \& Guerra (2013); Altmann (2009); Furlani (2007); Silva, Siqueira \& Rocha (2009) vem sinalizando que professores têm dificuldades no tratamento dessas questões. Em sala de aula, muitos docentes tendem a uma abordagem normatizadora e essencialista que pode reforçar estereótipos e preconceitos.

Nesse sentido, Britzman (2000) também discute que em relação à sexualidade, a cultura da escola é envolvida por respostas esperadas e desvinculadas das práticas sexuais. Isso ressalta a transmissão de informações já conhecidas pelos estudantes, muitas delas de caráter descritivo dos sistemas genitais, impedindo a possibilidade de surgimento de novas questões.

Os resultados da pesquisa de Souza \& Dinis (2010) coadunam com essas ideias ao abordarem que licenciandos em Ciências Biológicas também apresentam pouca disposição para falar abertamente sobre sexualidade na escola, ressaltando a heterossexualidade como a condição sexual natural e tratando estas questões como fixas.

Sobre isso, Foucault (1988) aborda que estamos sujeitos a manobras, táticas, técnicas e funcionamentos em que poderes repressivos fabricam corpos e induzem comportamentos. Sendo assim, também os discursos presentes nas aulas de Ciências foram produzidos para demarcação e naturalização de determinados valores, desconsiderando outros.

Ainda nesta discussão, Louro (2001) ressalta que a naturalização do binarismo masculino-feminino e da heterossexualidade contribui para perpetuação dos estereótipos. Além disso, geralmente, associamos o sexo ao gênero como uma única coisa numa ordem biológica incontestável (Butler, 2012). Assim, outras formas de pensar e viver os gêneros e as sexualidades são vistas como anormais, antinaturais e alvos de diversos preconceitos e discriminações.

Diante dessa problemática, este trabalho analisa uma proposta pedagógica sobre corpo, gênero e sexualidade desenvolvida no ensino de Ciências em uma turma de Educação de Jovens e Adultos (EJA) de uma escola pública municipal de Jequié-BA/Brasil. Vale ressaltar que essa proposta baseou-se em referenciais 
Revista Tecné, Episteme y Didaxis: TED. Año 2014, Número Extraordinario. ISSN Impreso: 0121-3814, ISSN web: 2323-0126

Memorias, Sexto Congreso Internacional sobre Formación de Profesores de Ciencias. 08 al 10 de octubre de 2014, Bogotá

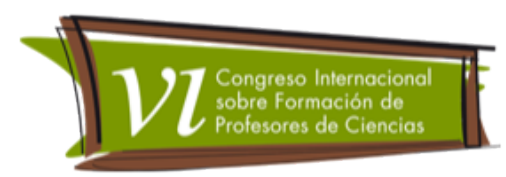

pós-críticos e em uma metodologia dialógica e problematizadora visando discutir a temática em questão para além do discurso biológico.

\section{Desenvolvimento}

A proposta foi desenvolvida em aulas de Ciências com discentes do $2^{\circ}$ segmento - $8^{\circ}$ e $9^{\circ}$ ano da EJA e teve a duração de uma unidade escolar, perfazendo um total de $35 \mathrm{~h} /$ aula. Inicialmente, houve uma explanação sobre a pesquisa, sendo solicitada a assinatura de um Termo de Consentimento/Assentimento Livre e Esclarecido. Vale destacar que antes de adentrar a sala de aula o projeto foi avaliado e aprovado pelo Comitê de Ética e Pesquisa da Universidade Estadual do Sudoeste da Bahia (UESB).

Dentre os temas discutidos durante a proposta, falamos sobre padrões corporais por meio da exposição e escolha de diferentes imagens de corpos; discutimos a produção dos corpos mediante a leitura e discussão de reportagens sobre uso de anabolizantes, silicones e cirurgias de lipoaspiração. Também abordamos sobre indivíduos intersex utilizando-se da exibição e interpretação do filme XXY e sobre a biologia dos corpos com representações esquemáticas da anatomia e fisiologia interna e externa do corpo de homem, mulher e intersex.

Ao falarmos sobre sexo e prazer elaborou-se uma "escala do prazer" discutindo sobre as padronizações das regiões erógenos do corpo; nesse viés discutimos também masturbação e desejo sexual. Para o trabalho com as demarcações de gênero, exibiu-se e debateu-se o vídeo Minha Vida de João, com a discussão de situações-problema. Conversamos também sobre diversidade de gênero e sexual (gays, lésbicas, heterossexual, travesti, bissexual, transexual) por meio de situações-problema e ao se enfocar o "universo trans" problematizou-se este tema com a exibição de uma entrevista com transexuais.

Tratamos também sobre riscos e vulnerabilidades por meio da montagem de cartaz coletivo com a turma sobre as múltiplas práticas sexuais e o contágio de doenças sexualmente transmissíveis. Ressalta-se que esta discussão surgiu por interesse dos discentes e não pela equipe organizadora. O debate sobre homofobia se deu por intermédio da apresentação de reportagens com exibição de situações/crimes homofóbicos e também da ida ao Centro de Cultura da cidade para assistir uma peça teatral "The Celio Cruz Show" que discute a homofobia na mídia e na família. 
Revista Tecné, Episteme y Didaxis: TED. Año 2014, Número Extraordinario. ISSN Impreso: 0121-3814, ISSN web: 2323-0126

Memorias, Sexto Congreso Internacional sobre Formación de Profesores de Ciencias. 08 al 10 de octubre de 2014, Bogotá

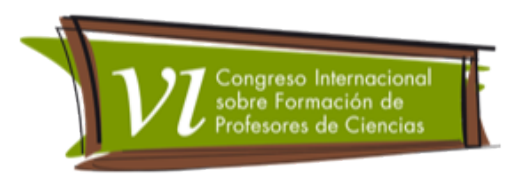

A intervenção encerrou-se com uma visita ao campus da universidade e da realização de uma dinâmica sobre relacionamentos afetivos-sexuais na contemporaneidade.

Ao longo das ações constatou-se que apesar de demonstrarem normatizações e conhecimentos superficiais e/ou estereotipados em relação aos temas trabalhados, os discentes aceitaram, aos poucos, participar das discussões e responder aos questionamentos. De forma dialógica, foram expondo seus pontos de vista, suas aflições e também seus preconceitos.

Por exemplo, sobre intersexualidade, muitos discentes vincularam as pessoas intersex como seres anômalos, indecisos, perturbados, doentes e propícios às correções médico-cirúgicas. Ressaltam-se essas passagens:

Se meu filho nascer assim, eu peço até pelo amor de Deus para o médico arrancar o pinto" (aluno a).

A partir de agora, toda vez que, toda vez que eu for transar, vou passar a mão para ver se tem uma vagina ou um pênis ou então, os dois, porque meu negócio é um só, eu sou homem" (aluno b).

Silva, Nunes \& Bento (2011) discutem essas questões ao abordarem que indivíduos intersex transitam nas expressões de legitimidade humana, e por isso são encarados como anomalias e/ou aberrações. Esses indivíduos revelam corpos vigiados, controlados e punidos por não se enquadrarem no modelo de masculino ou de feminino. Desta forma, as visões dos discentes se tornam exemplos claros de como poderes repressivos tentam enquadrá-los em lugares fixos e pré-estabelecidos (Foucault, 1988).

Na aula sobre biologia dos corpos, sexo, prazer e pontos eróticos, muitos alunos se sentiram incomodados com a abordagem sobre o prazer pelo sexo anal e pela relação homossexual ou bissexual demonstrando um pensamento associado à manutenção do eixo sexo-gênero, ressaltado por Butler (2012), reforçando também questões religiosas:

Não é certo sentir prazer pelos "infernos" (aluno c).

Vem da Bíblia, homem tem que gostar de mulher e mulher tem que gostar de homem (aluno d) 
Revista Tecné, Episteme y Didaxis: TED. Año 2014, Número Extraordinario. ISSN Impreso: 0121-3814, ISSN web: 2323-0126

Memorias, Sexto Congreso Internacional sobre Formación de Profesores de Ciencias. 08 al 10 de octubre de 2014, Bogotá

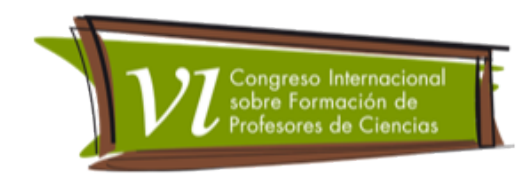

Deus fez o gato e a gata, fez o boi e fez uma vaca, Deus fez um homem e uma mulher (aluno a)

Pode sentir prazer por lá por trás, mas não é homem de jeito nenhum (aluno e).

Em meio a essas discussões, alguns discentes começaram a questionar a sexualidade da pesquisadora. Um aluno me perguntou se eu era lésbica, porque estava falando de prazer do homem da mulher tão abertamente. $O$ fato de ser uma professora e não um professor foi também abordado por eles como motivo para sua participação nas aulas.

Professora, a senhora gosta de homem ou de mulher? (aluno a).

Professora, a senhora é louca, né? Queria que fosse homem, aí eu queria ver se a senhora estava falando essas coisas (aluno c).

Se a senhora fosse homossexual eu não assistia suas aulas (aluno b).

Senti-me literalmente "sob fios de malabarismo" em sala de aula, tendo a minha própria sexualidade questionada por discutir questões da biologia dos corpos, por debater o prazer sem ter em mente padrões sociais e culturais de reforço da heterossexualidade, como comumente é feito por muitos professores. Além disso, precisava ressaltar, muitas vezes, que não estava obrigando-os a mudar seus desejos ou práticas sexuais, mas discutindo as múltiplas possibilidades dos corpos, dos gêneros e das sexualidades das pessoas e que todas, sem distinção, precisam ser reconhecidas nas suas singularidades, independente de nossa aceitação ou não. Isso foi gerando pouco a pouco mais reflexão e liberdade de expressão pelos discentes.

Com isso, tive meu próprio fazer docente colocado em xeque, era como se o fato de ter uma "identidade sexual" ou outra, ou o de me enquadrar em um gênero ou outro me tornasse mais ou menos capaz de abordar essas questões; autorizasse-me ou não a falar sobre isso. Talvez esses sejam alguns dos motivos pelos quais, os professores têm dificuldade em trabalhar a temática em sala de aula: lidar com sua própria sexualidade perante os discentes.

Sobre este aspecto, Hooks (2000) discute que no mundo público da aprendizagem institucional, o corpo tem de ser anulado e/ou passar despercebido. "Chamar atenção para o corpo é trair o legado de repressão e de negação que nos tem sido passado por nossos antecessores na profissão 
Revista Tecné, Episteme y Didaxis: TED. Año 2014, Número Extraordinario. ISSN Impreso: 0121-3814, ISSN web: 2323-0126

Memorias, Sexto Congreso Internacional sobre Formación de Profesores de Ciencias. 08 al 10 de octubre de 2014, Bogotá

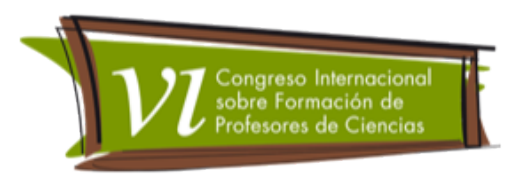

docente (Hooks, 2000, pág. 113)". Isso pode explicar porque a proposta gerou "suspeitas" por parte dos discentes. Diante disso, questionei-me como ficaria a situação de um professor que é gay, lésbica ou transexual? Como seria encarado pelos discentes?

No decorrer das discussões sobre diversidade sexual, transexualidade e homofobia, me chamou a atenção também o fato de alguns discentes começarem a reclamar que eu estava falando demais de "viado" ou de "gay". Alguns falaram assim:

Professora, quieta com esse papo. Esse assunto de gay tá mal (aluno f).

Ah, professora, de novo com essa conversa de viado, a senhora já falou tanto disso... (saiu da sala) (aluno a)

Professora, por que a senhora só fica falando de viado, não tem outros assuntos não? (aluno h).

Quero saber até onde a senhora quer chegar com essas coisas (aluno a).

Pode ser algo esperado o fato de alguns alunos rejeitarem a discussão sobre homossexuais, entretanto percebi por meio desse incômodo que a proposta estava de fato sendo desestabilizadora, provocando-os, tirando-os de um possível lugar tranquilo, fazendo-os pensar.

Apesar de estar sob a corda bamba em sala de aula, percebi o quanto a perspectiva autônoma, aberta e dialógica foi importante para a discussão da temática, sendo de extrema relevância que professores de Ciências tenham leituras e reflexões sobre as categorias de gênero e diversidade sexual na formação inicial e continuada para favorecer intervenções mais efetivas em sala de aula. Com isso não defendo que a discussão seja uma imposição, o que pode gerar o reforço de novas normas e impor o trabalho com a temática. Acredito que as pessoas precisam ter liberdade e autonomia para se abrir ou não a discussão, para perceber 0 eu no outro e também para lidar com as sexualidades.

Mesmo tendo minha sexualidade questionada e trabalhar sob "suspeita", a proposta permitiu amplas aprendizados em sala de aula, questionou normas e padrões, colocou discentes diante de situações problemáticas e desafiadoras, o 
Revista Tecné, Episteme y Didaxis: TED. Año 2014, Número Extraordinario. ISSN Impreso: 0121-3814, ISSN web: 2323-0126

Memorias, Sexto Congreso Internacional sobre Formación de Profesores de Ciencias. 08 al 10 de octubre de 2014, Bogotá

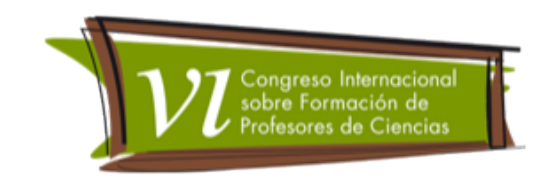

que possibilitou um (re) pensar sobre as diferentes situações vivenciadas no dia-adia.

\section{Referências Bibliográficas}

Altmann, H. (2009). Educação sexual em uma escola: da reprodução à prevenção. Cadernos de Pesquisa, 39 (136), 175-200.

Britzman, D. (2000). Curiosidade, sexualidade e currículo. In: G. L. Louro (org.), O corpo educado: pedagogias da sexualidade (2 ed) (61-82). Belo Horizonte: Autêntica.

Butler, J. (2012). Problemas de gênero: feminismo e subversão da identidade. (4 ed). Rio de Janeiro: Civilização Brasileira.

Foucalt, M. (1998). História da sexualidade 1: a vontade de saber. (13 ed). Rio de Janeiro: Edições Graal.

Furlani, J. (2007). Sexos, sexualidades e gêneros: monstruosidades no currículo da Educação Sexual. Educação em Revista, (46), 269-285.

Hooks, B. (2000). Eros, erotismo e o processo pedagógico. In: G. L. Louro (org.), O corpo educado: pedagogias da sexualidade (2 ed) (82-88). Belo Horizonte: Autêntica.

Louro, G. L. (2001). Dossiê Gênero e Educação. Estudos Feministas, 9 (2), 541-553.

Magalhães, C., \& Cruz, I. (2006). Sexualidade e Adolescência: prazer em viver. Rio de Janeiro: Booklink.

Silva, D. Q., \& Guerra, O. U. (2013). Educación sexual: estúdio comparativo entre escuelas en Brasil y en Cuba. Cadernos de Pesquisa, 43 (148), 280-301.

Silva, I. O., Siqueira, V. H. F., \& Rocha, G. W. F. (2009). Educação sexual e gravidez de adolescentes: significados construídos por docentes do curso de formação de professores em uma escola pública do Rio de Janeiro, Brasil. Revista Electrónica de Enseñanza de las Ciências, 8 (1), 216-231. Disponível em: http://www.webs.uvigo.es/reec

Silva, M. G., Nunes, K. A., \& Bento, B. (2011). Corpos marcados: a intersexualidade como (des) encaixes de gênero. Cronos: Revista de Pós-Grad. Ci. Soc, 12 (2), 128-142. 
Revista Tecné, Episteme y Didaxis: TED. Año 2014, Número Extraordinario. ISSN Impreso: 0121-3814, ISSN web: 2323-0126

Memorias, Sexto Congreso Internacional sobre Formación de Profesores de Ciencias. 08 al 10 de octubre de 2014, Bogotá

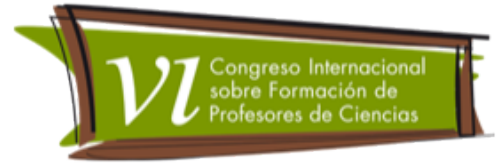

Silva, R. C. P., \& Megid Neto, J. (2006). Formação de professores e educadores para a abordagem da educação sexual na escola: o que mostram as pesquisas. Ciência \& Educação, 12 (2), 185-197.

Souza, C. L., \& DINIS, N. F. (2010). Discursos sobre homossexualidade e gênero na formação docente em biologia. Pro-Posições, 21 (3), 119-134. 